Predicting Crack Growth in Viscoelastic Bitumen under a Rotational Shear Fatigue Load $^{1}$

Yuqing Zhang, PhD

Lecturer in Highway Engineering

Aston Institute of Materials Research

School of Engineering and Applied Science

Aston University

Aston Triangle, Birmingham, B4 7ET, U.K.

Phone: +44 (0) 121-204-3391, Email: y.zhang10@aston.ac.uk

(Corresponding author)

Yangming Gao, $\mathrm{PhD}$ Candidate

Aston Institute of Materials Research

School of Engineering and Applied Science

Aston University

Aston Triangle, Birmingham, B4 7ET, U.K.

Phone: +44 (0) 121-204-3391, Email: gaoy14@aston.ac.uk

${ }^{1}$ This is an Accepted Manuscript of an article to be published by International Journal of Road Materials and Pavement Design. Access to the full text of the paper is available at https://doi.org/10.1080/14680629.2019.1635516 


\title{
Predicting Crack Growth in Viscoelastic Bitumen under a Rotational Shear Fatigue Load
}

\begin{abstract}
This study develops a damage mechanics-based crack growth model to predict crack length in a typical viscoelastic material (i.e., bitumen) under a rotational shear fatigue load. This crack growth model was derived using torque and dissipated strain energy equilibrium principles. The crack length was predicted using bitumen's shear moduli and phase angles in the undamaged and damaged conditions, measured by linear amplitude sweep (LAS) tests and time sweep (TS) tests, respectively. The two tests were both performed using Dynamic Shear Rheometer (DSR), thus the crack growth model was named as a DSR-C model. To validate the DSR-C model, the crack lengths after the TS tests were measured using digital visualisation of cracking surfaces for one virgin bitumen and one polymer-modified bitumen at two temperatures $\left(15,20^{\circ} \mathrm{C}\right)$, two frequencies $(10,20 \mathrm{~Hz})$ and two strain levels $(5 \%, 7 \%)$ under unaged and aged conditions. Results show that the DSR-C model can accurately predict the crack length in the viscoelastic bitumen under the rotational shear fatigue load at different loading and material conditions. The crack growth includes initial transition period, steady growth period and rapid growth period under a controlled strain loading mode. The degradation of the material property results from the crack growth that initiates from the outer edge toward the centre of the sample under the rotational shear load.
\end{abstract}

Keywords: Damage mechanics; shear fatigue; crack growth; bitumen; dynamic shear rheometer 


\section{Introduction}

Fatigue cracking is a primary distress in asphalt pavements and caused by a repeated traffic loading. The fatigue performance of asphalt pavements is strongly related to a bituminous binder that contributes to the rheology, cohesion and adhesion properties of asphalt mixtures (Gao, Dong, Li, Wang, \& Sun, 2015; Gao, Zhang, Yang, Zhang, \& Gu, 2019; Zhang, Luo, Luo, $\&$ Lytton, 2014). Therefore, accurate characterisation and quantification of the fatigue resistance of the bitumen are critical for optimising the asphalt mixture design and extending the service life of pavements.

Fatigue characterisation of bitumen has been a kernel research question in the past few decades. In the Strategic Highways Research Program (SHRP), a fatigue parameter $\left(\left|\mathrm{G}^{*}\right| \cdot \sin \delta\right)$ was proposed to evaluate the fatigue properties of bitumen at the intermediate temperatures (Anderson \& Kennedy, 1993), where $\left|\mathrm{G}^{*}\right|$ is shear modulus and $\delta$ is the phase angle and both are measured by dynamic shear rheometer (DSR). The parameter $\left(\left|\mathrm{G}^{*}\right| \cdot \sin \delta\right)$ should be minimized for the bitumen with a good resistance to fatigue cracking. However, it was found that the SHRP fatigue parameter is not correlated well to the fatigue life of asphalt mixtures and pavements (Bahia, Zhai, Zeng, Hu, \& Turner, 2001; Planche, Anderson, Gauthier, Hir, \& Martin, 2004; Tsai \& Monismith, 2005; Zhou, Mogawer, Li, Andriescu, \& Copeland, 2013). This is fundamentally due to that the shear modulus $\left(\left|\mathrm{G}^{*}\right|\right)$ and the phase angle $(\delta)$ in the DSR tests were obtained within the linear viscoelastic region of bitumen without accounting for the damaging effect. This is particularly true for polymer-modified bitumen which can sustain a higher strain before cracking damage has occurred. Consequently, different approaches were developed to improve the fatigue characterisation for bitumen. In the National Cooperative Highway Research Program (NCHRP) project 9-10, the time sweep (TS) repeated cyclic loading test using the DSR was introduced to study the fatigue behaviours of the bitumen (Bahia, Zeng, Khatri, Zhai, \& Anderson, 2001). The TS test has been successfully used for defining fatigue failure and criteria of bitumen (Planche, Anderson, Gauthier, Hir, \& Martin, 2004; Anderson, Hir, Marasteanu, Planche, Martin, \& Gauthier, 2001; Bonnetti, Nam, \& Bahia 2002; Wang, Zhang, Castorena, Zhang, \& Kim, 2016). Based on the fatigue data of the TS test, the dissipated energy concept has been widely used for bitumen fatigue analysis through providing the alternative definitions of fatigue failure, including the dissipated energy ratio (DER) (Anderson, Hir, Marasteanu, Planche, Martin, \& Gauthier, 2001; Bonnetti, Nam, \& Bahia 2002; Ghuzlan \& Carpenter, 2000; Martono, Bahia, \& Angelo, 2007) and the ratio of dissipated energy change (RDEC) (Shen \& Carpenter, 2005; Shen, Airey, Carpenter, \& Huang, 
2006; Shen, Chiu, \& Huang, 2010). The dissipated energy parameters (DER and RDEC) are indirect and empirical indicators for defining fatigue failure of bitumen. Moreover, the linear amplitude sweep (LAS) test was developed as an accelerated fatigue procedure. The test is performed at constant temperature and frequency with an increasing strain amplitude to measure the bitumen damage tolerance. The LAS test has been used to develop a fatigue law based on the viscoelastic continuum damage (VECD) mechanics (Hintz, Velasquez, Johnson, \& Bahia, 2011; Hintz, \& Bahia, 2013a; Wang, Castorena, Zhang, \& Kim 2015; Safaei \& Castorena 2016; Safaei, Castorena, \& Kim, 2016; Safaei \& Castorena, 2017). However, the fatigue damage mechanisms of bitumen require further studies from the fundamental mechanical perspective of crack growth, e.g., how the crack grows in the bitumen under the rotational shear force. Moreover, none was able to directly predict the crack growth in terms of crack length in the bitumen which can serve as a direct evaluation of the bitumen's resistance to the fatigue cracking.

To understand the damage mechanism leading to bitumen fatigue, there is a need to investigate the cracking process, i.e., crack propagation, under the rotational shear fatigue loading. A better fatigue crack prediction can improve the fundamental understanding and the grading system of the bitumen in terms of fatigue performance. Some existing studies have been started to focus on the direct investigations of the crack growth in the bitumen, for instance, Hintz et al. (2013b) used the time sweep (TS) testing in the DSR and the digital visualisation to investigate the trends in the crack growth of the bitumen samples. Shan et al. (2017) employed the DSR testing and the image analysis method to determine the internal crack growth of the bitumen samples during a shear fatigue process. In these studies, Eq. (1) was used to predict the effective radius based on the decrease of the measured torque $(T)$ with the number of load cycles in the TS test.

$$
r_{E}^{4}=\frac{2 T h}{\pi \theta\left|G_{0}^{*}\right|}
$$

where $r_{E}$ is the effective radius shown in Figure 1 which is the radius of the remaining uncracked area of the bitumen sample in the DSR test; $T$ and $\theta$ are the torque and the deflection angle measured by DSR, respectively; $h$ is the height of the sample; and $\left|G_{0}^{*}\right|$ is the shear modulus of the undamaged bitumen. 


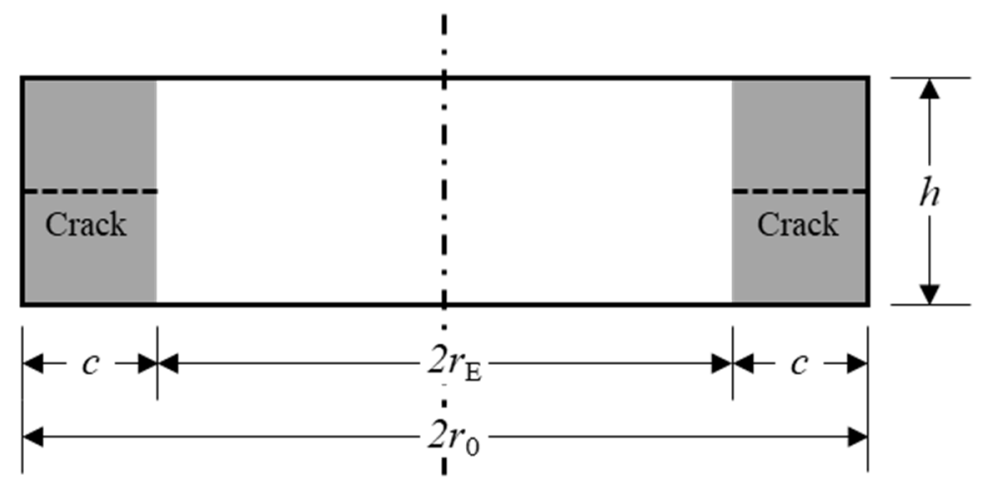

Figure 1. Schematic side view of cylindrical sample in dynamic shear rheometer (DSR) tests. (The crack length $c=r_{0}-r_{\mathrm{E}}$, where $r_{\mathrm{E}}$ is the effective radius, $r_{0}$ is the original radius, and $h$ is the height of the bitumen sample, and in this study, $r_{0}=4 \mathrm{~mm}$ and $h=2 \mathrm{~mm}$.)

Then the crack length in the DSR test was determined by subtracting the effective radius determined by Eq. (1) from the original sample radius. It was found the crack length was less than the measured values from the digital image analysis, particularly at a relatively larger number of load cycles (Hintz \& Bahia, 2013b; Shan, Tian, He, \& Ren, 2017). This is fundamentally due to the fact that Eq. (1) is derived based on a linearly elastic stress-strain constitutive relation at the undamaged condition thus cannot be used to predict the effective radius which results from the fatigue crack growth at the damaged condition. An assumption was made for Eq. 1 that the shear modulus $\left|\mathrm{G}^{*}\right|$ in the damaging DSR test was assigned as a constant $\left|G^{*}\right|$ that is the shear modulus for the bitumen at the undamaged DSR test. This assumption needs a more solid justification or it can lead to significant systematic errors in the prediction of the crack growth in the DSR test. Therefore, a further study based on damage mechanics is needed to better understand the fatigue damage process and predict the crack growth of the bitumen in the DSR test.

The objective of this study is to employ damage mechanics principles and develop a DSRbased crack growth (DSR-C) model to accurately predict the crack growth in the whole process of the DSR test, so as to provide a direct method to effectively quantify the fatigue resistance of the bitumen. Using the torque and dissipated strain energy (DSE) equilibrium principles of damage mechanics, a mechanical model was developed to predict the crack growth of the bitumen sample under a rotational shear fatigue load. The DSR tests were conducted to determine the model parameters and digital visualisation of the cracking surfaces was used to measure the crack length in order to validate the DSR-C prediction model. The process of the crack growth in the bitumen sample under shear fatigue loading was analysed using the developed mechanical model. 


\section{Mechanical modelling fatigue damage in bitumen under a rotational shear fatigue load}

\subsection{Linear viscoelastic analysis of bitumen in an undamaged condition}

The linear viscoelastic analysis of the bitumen under an undamaged condition is firstly presented. For a strain-controlled cyclic load in the undamaged condition, the strain amplitude is relatively small (e.g., $<1 \%$ ), within which the shear modulus and phase angle of the bitumen remain unchanged at different strain levels. In this case, a controlled shear strain is expressed as

$$
\gamma(t)=\gamma_{0} \sin (\omega t)
$$

and the corresponding shear stress response at the undamaged condition is

$$
\tau(t)=\tau_{0} \sin \left(\omega t+\delta_{0}\right)
$$

where $\gamma_{0}$ and $\tau_{0}$ are the strain amplitude and the stress amplitude $(\mathrm{kPa})$, respectively; $\omega$ is the loading frequency in $\mathrm{rad} / \mathrm{sec}, t$ is the loading time in seconds, and $\delta_{0}$ is the phase angle of the bitumen at the undamaged condition in radian.

The strain amplitude at a given radial position in a cylindrical bitumen sample is defined as

$$
\gamma_{0}(r)=\frac{\theta_{0}}{h} r \text { with } 0 \leq r \leq r_{0}
$$

where $\theta_{0}$ is the amplitude of deflection (rotational) angle in radian, $r_{0}$ and $h$ are the radius (mm) and the height $(\mathrm{mm})$ of the cylindrical sample, respectively. It is noted that the rotation amplitude $\theta_{0}$ is controlled by DSR directly.

According to the linear viscoelastic stress-strain law and Eq. (4), the stress amplitude at a given radial position of the sample at the undamaged condition can be expressed as

$$
\tau_{0}(r)=\left|G_{0}^{*}\right| \gamma_{0}(r)=\frac{\left|G_{0}^{*}\right| \theta_{0}}{h} r \text { with } 0 \leq r \leq r_{0}
$$

where $\left|G_{0}^{*}\right|$ is the shear modulus $(\mathrm{kPa})$ of the bitumen at the undamaged condition. It is found from Eq. (5) that the stress amplitude has a linear relationship with the radius $(r)$ of the sample. The stress amplitude increases along the radial direction from the centre to the edge of the sample. When $r=r_{0}$, the stress amplitude reaches its maximum value: 


$$
\tau_{0 \max }=\frac{\left|G_{0}^{*}\right| \theta_{0}}{h} r_{0}
$$

where $\tau_{0 \max }$ is the maximum stress amplitude $(\mathrm{kPa})$ at the undamaged condition, which occurs at the edge of the cylindrical sample. Then, the stress amplitude at a given radial position can be also expressed as

$$
\tau_{0}(r)=\frac{r}{r_{0}} \tau_{0 \max } \text { with } 0 \leq r \leq r_{0}
$$

The torque amplitude measured by DSR directly on the cylindrical bitumen sample at the undamaged condition is defined by Eq. (8).

$$
T_{0}=\int_{0}^{r_{0}} \tau_{0} \cdot 2 \pi r \cdot r \cdot d r=\frac{\pi r_{0}^{3}}{2} \tau_{0 \max }
$$

Bitumen is a kind of viscoelastic material. When bitumen is subjected to cyclic fatigue loading, in each cycle, the stress-strain curve follows a hysteresis loop in a loading and unloading processes. The area inside the loop is defined as the dissipated strain energy (DSE) density. The DSE concept has been widely used for asphalt mixtures (Lytton, Zhang, Gu, \& Luo, 2018; Zhang, Gu, Birgisson, \& Lytton, 2018). The DSE density at a given radial position of the bitumen sample at the undamaged condition in one load cycle can be calculated by

$$
D S E_{0}(r)=\int_{t_{0}}^{t_{0}+\frac{2 \pi}{\omega}} \tau(t) d \gamma(t)=\pi \tau_{0}(r) \gamma_{0}(r) \sin \delta_{0}
$$

where the strain amplitude $\gamma_{0}(r)=\frac{\tau_{0}(r)}{\left|G_{0}^{*}\right|}$, thus Eq. (9) can be further written as

$$
D S E_{0}(r)=\pi \tau_{0}(r)^{2} \frac{\sin \delta_{0}}{\left|G_{0}^{*}\right|}
$$

\subsection{Nonlinear viscoelastic analysis of bitumen in a damaged condition}

The nonlinear viscoelastic behaviour of the bitumen at the damaged condition is analysed under a strain-controlled rotational shear load. The bitumen is regarded as damaged when the strain amplitude is relatively high, at which the shear modulus and phase angle change with load cycles and strain levels. The controlled shear strain at the damaged condition is assumed as

$$
\gamma_{d}(t)=\gamma_{d} \sin (\omega t)
$$


and the measured shear stress is expressed as

$$
\tau_{N}(t)=\tau_{N} \sin \left(\omega t+\delta_{N}\right)
$$

where $\delta_{N}$ is the phase angle (in radian) of the bitumen at the $N$ th load cycle at the damaged condition that changes with the load cycle; $\gamma_{d}$ is the strain amplitude at the damaged condition; and $\tau_{N}$ is the stress amplitude $(\mathrm{kPa})$ at the damaged condition that changes with the load cycle $N$. It is note that both the strain amplitude $\gamma_{d}$ and the stress amplitude $\tau_{N}$ are a function of the radius $(r)$ of the sample.

The shear modulus of the bitumen at the damaged condition is defined as

$$
\left|G_{N}^{*}\right|=\frac{\tau_{N}(r)}{\gamma_{d}(r)}
$$

Note that the shear modulus $\left|G_{N}^{*}\right|$ at the damaged condition will decrease with load cycle due to the degradation of the materials. Comparable to Eq. (6), the maximum stress amplitude of the bitumen sample at the $N$ th load cycle under the damaged condition can be expressed as:

$$
\tau_{N \max }=\frac{\left|G_{N}^{*}\right| \theta_{0}}{h} r_{0}
$$

Thus, the torque amplitude measured by DSR directly at the Nth load cycle is determined as:

$$
T_{N}=\frac{\pi r_{0}^{3}}{2} \tau_{N \max }
$$

The dissipated strain energy density at a given radial position of the cylindrical bitumen sample at the damaged condition and the $N$ th load cycle can be formulated as

$$
D S E_{N}(r)=\int_{(N-1) \frac{2 \pi}{\omega}}^{N \frac{2 \pi}{\omega}} \tau_{N}(t) d \gamma_{d}(t)=\pi \tau_{N}(r) \gamma_{d}(r) \sin \delta_{N}
$$

where the strain amplitude $\gamma_{d}(r)=\frac{\tau_{N}(r)}{\left|G_{N}^{*}\right|}$. Eq. (16) can be further expressed as

$$
D S E_{N}(r)=\pi \tau_{N}(r)^{2} \frac{\sin \delta_{N}}{\left|G_{N}^{*}\right|}
$$




\subsection{Prediction of crack growth in DSR using damage mechanics}

The crack in the DSR cylindrical sample manifests as an 'edge crack' under the cyclic shear loading in the DSR test. The edge crack is a circumferential crack that initiates at the periphery of the sample and propagates toward the centre of the sample, based on the laboratory observations of the existing studies (Hintz \& Bahia, 2013b; Shan, Tian, He, \& Ren, 2017; Aboutorabi, Ebbot, \& Gent, 1998). Figure 1 shows the schematic side view of the cylindrical sample and the cracking path in the sample under the cyclic shear load. The cracking path was proposed and verified based on the laboratory observations of the cracking surfaces in the DSR tests in the literature (Hintz \& Bahia, 2013b; Shan, Tian, He, \& Ren, 2017). In Figure 1, ro is the original radius of the cylindrical bitumen sample and $h$ is the height of the sample. In this study, $r_{0}=4 \mathrm{~mm}$ and $h=2 \mathrm{~mm}$. When crack grows, it starts from the sample edge and propagates towards the centre and $c$ is the crack length. The radius of the remaining un-cracked areas is $r_{E}$ that is defined as the effective radius of the sample, thus the crack length can be calculated as $c=r_{0}-r_{E}$.

Some researchers have reported the instability of the cracking known as "edge flow" occurring in the sample at the initiation stage of the DSR testing. The edge flow is not a true cracking phenomenon, which is caused by edge instability resulting from the development of the normal forces (Keentok \& Xue, 1999; Anderson, Hir, Marasteanu, Planche, Martin, \& Gauthier, 2001). Hintz et al. (2011) have analysed the normal forces during time sweep testing and found that the normal stresses were negligible compared with the torsional stresses during the binder fatigue testing. It has also been demonstrated that the edge effect could be considered to have no significant effect on parallel plate fatigue testing (Martono, Bahia, \& Angelo, 2007) and the edge instability was ruled out as a cause of damage (Hintz \& Bahia, 2013b). In this study, the edge instability is negligible and does not affect the crack growth measurement because a) the normal forces were found very small $(<0.1 \mathrm{~N})$ and declined very quickly with load cycles; and b) the high shear strain level (5\%) was used so that the sample exhibits damaging from the first load cycle. Thus, the damage mechanics concepts can be applied for characterisation and prediction of the fatigue cracking in bitumen under a rotational shear fatigue load.

To determine the effective radius and the crack length of the cylindrical bitumen sample at the $N$ th load cycle during the shear fatigue process, two equilibrium principles of damage mechanics were employed including torque equilibrium principle and dissipated strain energy (DSE) equilibrium principle, which hypothesized that the torque and the DSE in the apparent 
(damaged) configuration of the bitumen were equivalent to those in the effective (undamaged) configuration, respectively. It is noted that this study utilised the fundamental energy equilibrium hypothesis from damage mechanics and built the balance equation between the two conditions (undamaged and damaged) of the material, but ignored the process how the material evolves from the undamaged condition to the damaged conditions. Thus the prediction of the cracking damage will use the material properties at the two conditions only. In contrast, this method does not require the material property information during the damage evolution process of the material, e.g., how the material evolves from linear viscoelastic condition to nonlinear viscoelastic condition and to the damage condition. The crack length measured from image analysis of the crack surfaces in bitumen will validate the prediction accuracy of the model, demonstrating that the equilibrium hypothesis of total dissipated strain energy in this damage mechanics framework is valid.

According to the torque amplitude equilibrium principle, the measured torque $\left(T_{\mathrm{N}}\right)$ at the $N$ th load cycle for the damaged configuration (with a radius of $r_{0}$ ) is equivalent to the effective torque ( $\left.T_{\mathrm{E}}\right)$ for the undamaged configuration (with a radius of $r_{\mathrm{E}}$ ), as expressed in Eq. (15).

$$
T_{N}=T_{E}
$$

Based on Eqs. (15) and (8), Eq. (18) can be further written as

$$
\frac{\pi r_{0}^{3}}{2} \tau_{N \max }=\frac{\pi r_{E}^{3}}{2} \tau_{E \max }
$$

where $\tau_{\mathrm{Nmax}}$ is defined by Eq. (14), and $\tau_{\mathrm{Emax}}$ is the effective stress amplitude maximum for the undamaged configuration, defined by Eq. (6) by replacing $r_{0}$ with $r_{\mathrm{E}}$.

According to the energy equilibrium principle for the entire volume of the cylindrical sample, the dissipated strain energy $\left(D S E_{\mathrm{N}}\right)$ at the $N$ th load cycle for the damaged configuration is equivalent to the effective dissipated strain energy $\left(D S E_{\mathrm{E}}\right)$ for the undamaged configuration, as shown in Eq. (20).

$$
\iiint_{V_{0}} D S E_{N}(r) d V_{0}=\iiint_{V_{E}} D S E_{E}(r) d V_{E}
$$

where $V_{0}$ is the total volume of the damaged bitumen sample that has a radius of $r_{0}$ and the material properties are those at the damaged conditions including $\left|G_{N}^{*}\right|$ and $\delta_{N}$. $V_{\mathrm{E}}$ is the volume of the undamaged bitumen which has a radius of $r \mathrm{E}$ and the material properties are 
those at the undamaged conditions including $\left|G_{0}^{*}\right|$ and $\delta_{0}$. Substituting Eqs. (17) and (10) into Eq. (20) gives

$$
\int_{0}^{r_{0}} \pi \tau_{N}(r)^{2} \frac{\sin \delta_{N}}{\left|G_{N}^{*}\right|} \cdot 2 \pi r \cdot h \cdot d r=\int_{0}^{r_{E}} \pi \tau_{E}(r)^{2} \frac{\sin \delta_{0}}{\left|G_{0}^{*}\right|} \cdot 2 \pi r \cdot h \cdot d r
$$

It is noted that the dissipated strain energy, rather than the dissipated strain energy density, was used to build the energy equilibrium equation.

Solving Eqs. (19), (21) and (7), the effective radius (see Figure 1) of the cylindrical bitumen sample at the $N$ th load cycle can be obtained as Eq. (22) and the crack length can be calculated by Eq. (23).

$$
\begin{gathered}
r_{E}=\left(\frac{\left|G_{N}^{*}\right| / \sin \left(\delta_{N}\right)}{\left|G_{0}^{*}\right| / \sin \left(\delta_{0}\right)}\right)^{\frac{1}{4}} r_{0} \\
c=\left[1-\left(\frac{\left|G_{N}^{*}\right| / \sin \left(\delta_{N}\right)}{\left|G_{0}^{*}\right| / \sin \left(\delta_{0}\right)}\right)^{\frac{1}{4}}\right] r_{0}
\end{gathered}
$$

The DSR-based crack growth (DSR-C) model (Eq. 23) provides a mechanics model to directly determine the crack growth (crack length, $c$ vs. load cycle, $N$ ) of a bitumen with an original radius of $r_{0}$ in a cyclic and rotational shear test such as DSR test using the material properties including shear modulus and phase angle. It is emphasized that $\left|G_{0}^{*}\right|$ and $\delta_{0}$ are the shear modulus and phase angle of the bitumen at the undamaged condition (relatively low strain level, e.g., $<1 \%$ at room temperature); $\left|G_{N}^{*}\right|$ and $\delta_{N}$ are the shear modulus and phase angle of the bitumen at the $N$ th load cycle which change with the load cycle as the bitumen was subjected to the damaged condition (relatively high strain level, e.g., $>5 \%$ at room temperature). The following laboratory test measurement of the crack growth will demonstrate the reliability and accuracy of the DSR crack growth prediction model in Eq. (23).

\section{Materials and methods}

\subsection{Materials}

Two different bitumens were considered in this study: a bitumen X-70 (bitumen A) and a 
bitumen 40/60 (bitumen B) where bitumen A is a polymer modified bitumen and bitumen B is an unmodified bitumen. Bitumen A and bitumen B were tested before and after Thin-Film Oven Test (TFOT) laboratory aging that was conducted at the temperature of $163{ }^{\circ} \mathrm{C}$ for 5 hours. These bitumens are referred to as $A_{v}$ and $B_{v}$ before aging and $A_{a}$ and $B_{a}$ after aging, respectively.

\subsection{Sample preparation}

In this study, the bitumen samples were prepared following the AASHTO T 315 "Determining the Rheological Properties of Asphalt Binder Using a Dynamic Shear Rheometer (DSR)". The standard specimen geometry ( $8 \mathrm{~mm}$ in diameter with $2 \mathrm{~mm}$ height) was employed for all tests due to the testing temperature of $20^{\circ} \mathrm{C}$. The samples were prepared using the silicone mould. The hot bitumen from a heated container was poured into the mould to form a convex surface and then the filled mould was cooled to room temperature without chilling. Then, the bitumen was loosened from the mould by flexing the rubber mould and was adhered to the preheated lower test plate by gently pressing the convex (top) surface of the pellet. After that, the upper test plate was moved until the gap between the plates equals the testing gap ( $2 \mathrm{~mm}$ ) plus the gap closure required to create a slight bulge at the outside face of the test specimen. The excess bitumen was trimmed by moving a heated trimming tool around the edges of the plates so that the bitumen is flush with the outer diameter of the plates. When the trimming is complete, the gap is decreased to the testing value $(2 \mathrm{~mm})$. Finally, the bitumen was heated to the testing temperature and then remained for 5 minutes before loading.

\subsection{Test methods}

Laboratory testing was conducted using a Kinexus DSR from Malvern Panalytical with 8-mm diameter parallel plate geometry. Two types of shear fatigue tests, linear amplitude sweep (LAS) test and time sweep (TS) test, were performed. Two replicates were tested at each testing condition and a third replicate was tested when the deviation was greater than 10 percent. The measured results were analysed based on the averaged data.

The linear amplitude sweep (LAS) tests were conducted to obtain the shear modulus $\left(\left|G_{0}^{*}\right|\right)$ and the phase angle $\left(\delta_{0}\right)$ of the bitumen under the undamaged condition and to determine the controlled strain levels for the later TS fatigue damage tests. The strain amplitudes ranged from $0.1 \%$ to $30 \%$ linearly. The shear modulus and phase angle were recorded with the increasing strain amplitudes. Figure 2 shows the results of the LAS tests at $20^{\circ} \mathrm{C}$ and $10 \mathrm{~Hz}$ for all the 
tested bitumen including the virgin polymer modified bitumen $\mathrm{X}-70\left(\mathrm{~A}_{\mathrm{v}}\right)$, aged bitumen $\mathrm{X}-70$ $\left(A_{a}\right)$, virgin unmodified bitumen 40/60 $\left(B_{v}\right)$ and aged bitumen 40/60 $\left(B_{a}\right)$. The undamaged shear modulus $\left(\left|G^{*} 0\right|\right)$ and the phase angle $\left(\delta_{0}\right)$ were determined as the average values of the test data in the linear viscoelastic region (plateau stage) of the LAS test where the modulus or phase angle doesn't change with the strain levels, as shown in Figure 2(a). It is found from Figure 2(b) that the aged bitumen $\left(\mathrm{A}_{\mathrm{a}}\right.$ or $\mathrm{B}_{\mathrm{a}}$ ) has a higher shear modulus and a lower phase angle than the unaged bitumen $\left(A_{v}\right.$ or $\left.B_{v}\right)$, which indicates that the bitumen becomes stiffer after oxidative aging. Thus, the aged bitumen trends to have a weaker fatigue resistance that will be validated by the crack length under a rotational shear fatigue load later. The strain sweep tests were performed at two temperatures $\left(15\right.$ and $\left.20^{\circ} \mathrm{C}\right)$ and two loading frequencies (10 and $20 \mathrm{~Hz})$, as shown in Table 1. The shear modulus $\left(\left|G^{*}\right|\right)$ and phase angle $\left(\delta_{0}\right)$ of the bitumen under the undamaged condition were also determined at those selected temperatures and loading frequencies. The strain levels (5\% and 7\%) were selected for TS fatigue damage tests in the nonlinear region of the LAS test conducted on all the tested bitumens at different temperatures or loading frequencies to induce damage. The images of cracking surfaces of bitumen sample shown in Section 4.1 indicate that the applied strain levels were high enough to introduce the cracking damage in the TS tests for all the tested bitumens. In fact, the $5 \%$ and $7 \%$ strain levels have been used in the literature for the TS tests to study the fatigue damage behaviour of bitumen (Wang, Castorena, Zhang, \& Kim 2015; Wang, Zhang, Castorena, Zhang, \& Kim, 2016).

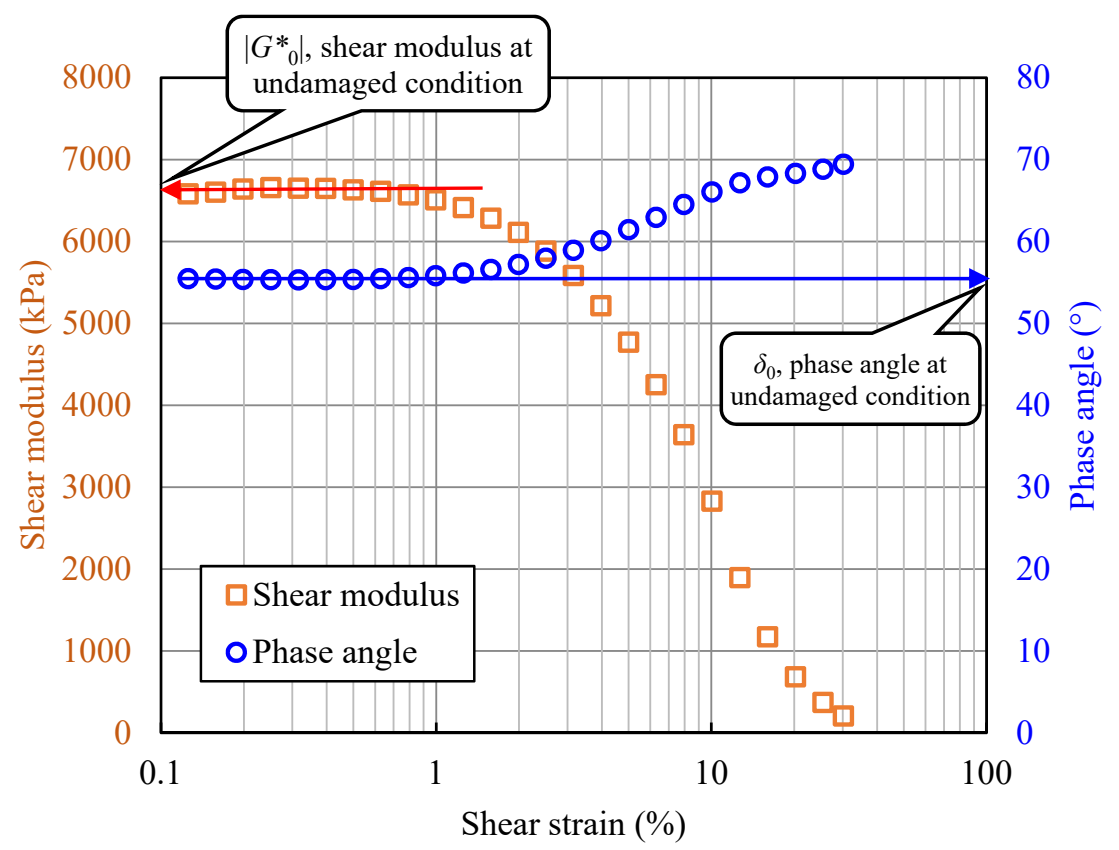

(a) 


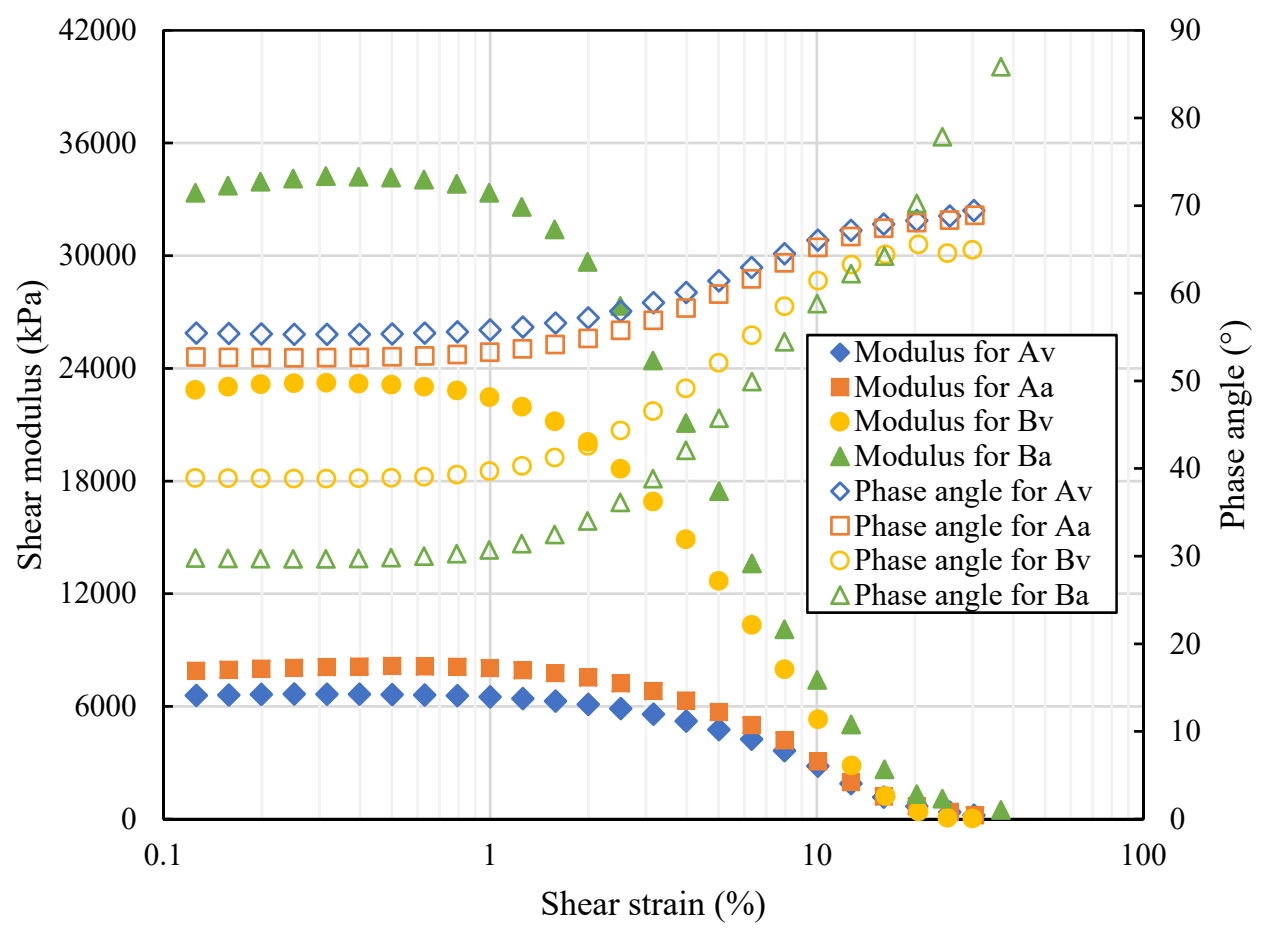

(b)

Figure 2. Results of linear amplitude sweep (LAS) tests at $20^{\circ} \mathrm{C}$ and $10 \mathrm{~Hz}$. (a) Shear modulus $\left(\left|G_{0}^{*}\right|\right)$ and phase angle $\left(\delta_{0}\right)$ are determined from LAS test for the unaged polymer modified bitumen X$70\left(A_{v}\right)$. (b) LAS test results for virgin polymer modified bitumen $X-70\left(A_{v}\right)$, aged bitumen X-70 $\left(A_{a}\right)$, virgin unmodified bitumen 40/60 $\left(B_{v}\right)$ and aged bitumen 40/60 $\left(B_{a}\right)$. Time sweep (TS) tests were conducted to obtain the shear modulus $\left(\left|G_{\mathrm{N}}^{*}\right|\right)$ and the phase angle $\left(\delta_{\mathrm{N}}\right)$ with the number of load cycles for the bitumen under the damaged condition. In this study, the TS tests were performed using sinusoidal loading with the rotation amplitudes of 0.025 and $0.035 \mathrm{rad}$, respectively, in order to achieve the target strain amplitudes $(5 \%$ and $7 \%)$ at the edge of the sample $\left(r=r_{0}\right)$. The applied strain levels were determined from the above LAS tests at which the bitumen has been in the damaged condition. In order to validate the DSR crack growth model in Eq. (23), the TS tests were performed at different experimental conditions, summarised in Table $\mathbf{1}$. The test temperatures $\left(15\right.$ and $\left.20^{\circ} \mathrm{C}\right)$ were selected to consider the intermediate temperatures when a fatigue cracking happens. The test frequencies (10 and $20 \mathrm{~Hz})$ and strain levels $(5 \%$ and $7 \%)$ were selected to produce fatigue cracking damage within a reasonable load cycle. The quality of the raw data obtained at the high frequency of $20 \mathrm{~Hz}$ was reviewed in the TS test. It was found that the constant shear strain (5\%) was well controlled for the full loading history, which means that the DSR data obtained at $20 \mathrm{~Hz}$ is reliable.

Table 1. Shear fatigue testing plan.

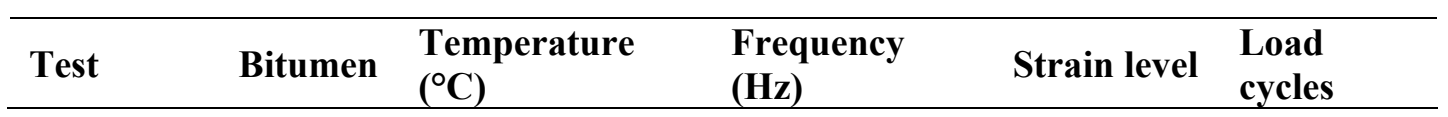




\begin{tabular}{|c|c|c|c|c|c|}
\hline \multirow{2}{*}{$\begin{array}{l}\text { Linear } \\
\text { Amplitude } \\
\text { Sweep } \\
\text { (LAS) }\end{array}$} & $A_{v}$ & $\begin{array}{l}20 \\
15 \\
20\end{array}$ & $\begin{array}{l}10 \\
10 \\
20\end{array}$ & $0.1 \%-30 \%$ & NA \\
\hline & $\begin{array}{l}\mathrm{B}_{\mathrm{v}} \\
\mathrm{A}_{\mathrm{a}} \\
\mathrm{B}_{\mathrm{a}} \\
\end{array}$ & 20 & 10 & $0.1 \%-30 \%$ & NA \\
\hline \multirow{6}{*}{$\begin{array}{l}\text { Time } \\
\text { Sweep } \\
\text { (TS) }\end{array}$} & \multirow{4}{*}{$A_{v}$} & 20 & 10 & $5 \%$ & $\begin{array}{l}7200 \\
24000 \\
42000\end{array}$ \\
\hline & & 15 & 10 & $5 \%$ & \multirow{3}{*}{24000} \\
\hline & & 20 & 20 & $5 \%$ & \\
\hline & & 20 & 10 & $7 \%$ & \\
\hline & $\mathrm{B}_{\mathrm{v}}$ & 20 & 10 & $5 \%$ & $\begin{array}{l}7200 \\
24000 \\
42000\end{array}$ \\
\hline & $\begin{array}{l}\mathrm{A}_{\mathrm{a}} \\
\mathrm{B}_{\mathrm{a}}\end{array}$ & $\begin{array}{l}20 \\
20 \\
\end{array}$ & $\begin{array}{l}10 \\
10 \\
\end{array}$ & $\begin{array}{l}5 \% \\
5 \%\end{array}$ & 24000 \\
\hline
\end{tabular}

Note: $A_{v}, B_{v}, A_{a}$ and $B_{a}$ stand for the virgin X-70 bitumen (polymer modified), the virgin 40/60 bitumen (unmodified), the aged X-70 bitumen and the aged 40/60 bitumen, respectively.

Figure 3 shows a typical result of the TS test which is for the unaged X-70 bitumen. The test was controlled at a constant strain $(5 \%)$, a temperature of $20^{\circ} \mathrm{C}$ and a loading frequency of $10 \mathrm{~Hz}$. The shear modulus was observed to decrease with load cycles and the phase angle increases to a peak and then decreases with load cycles in the TS test. It should be noted that, at a high strain level (e.g., 5\%), cracking damage can lead to not only the decrease of shear modulus but the increase of phase angle. Characterising both changes is critical to accurately model the fatigue performance of bitumen. In fact, it has been reported in the literature (Wang, Castorena, Zhang, \& Kim 2015; Wang, Zhang, Castorena, Zhang, \& Kim, 2016) that the phase angle increases up to a peak during the fatigue tests and this peak was used to define the fatigue failure of bitumen.

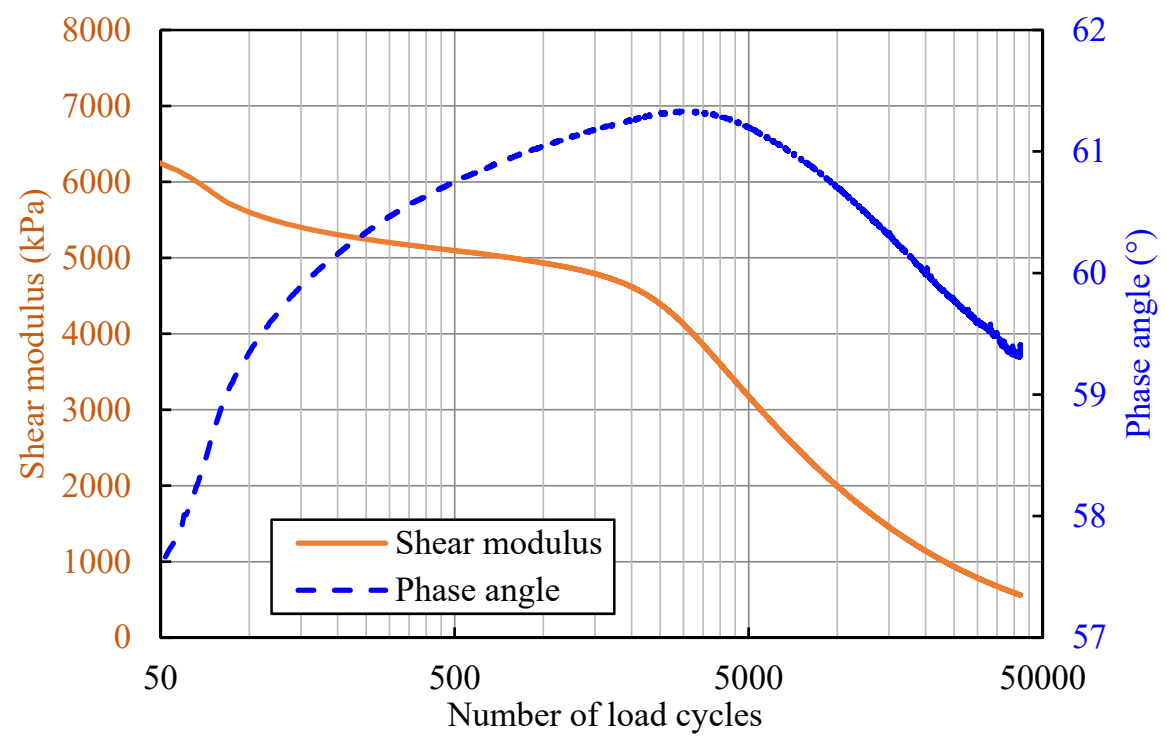


Figure 3. Results of time sweep (TS) test at $5 \%$ strain, $20{ }^{\circ} \mathrm{C}$ and $10 \mathrm{~Hz}$ including shear modulus $\left(\left|G_{\mathrm{N}}^{*}\right|\right)$ and phase angle $\left(\delta_{\mathrm{N}}\right)$ for the unaged X-70 bitumen with load cycles.

After the time sweep (TS) test, the crack surface morphological pattern of the bitumen sample needs to be obtained in order to measure the effective radius $\left(r_{\mathrm{E}}\right)$ of the un-cracked areas of the sample so that the crack length can be determined using $c=r_{0}-r_{\mathrm{E}}$. The temperature of the sample was reduced to $3{ }^{\circ} \mathrm{C}$ immediately after the TS test and maintained for $10 \mathrm{~min}$ to freeze the crack surface pattern thoroughly. Then, the top DSR loading platen was directly pulled off from the bottom platen. The bitumen sample's top and bottom surfaces were photographed and the image processing was used to determine the effective radius, which will be detailed in the next Section.

\section{Results and discussion}

\subsection{Definition and measurement of crack length}

A typical image of the bitumen cracking surface after the time sweep (TS) test is presented in Figure 4(a). It is observed from this image that the bitumen surface shows distinct morphological patterns at different areas. In the central area of the bitumen sample, it shows a flat and smooth surface which is caused by the direct tensile pull-off (Mode-I fracture) after the TS test. Thus this central area represents the uncracked portion of the sample during the TS test, whose radius is defined as the effective radius $(r \mathrm{E})$. Surrounding this central area, a ring area with rough surfaces exists consisting of the radial peaks and valleys, which results from the shear-induced surface interactions between the top and bottom crack faces. This type of cracking morphology is referred to as 'factory roof' (Tschegg, Ritchie, \& McClintock, 1983). It is believed that this ring area is caused by the cracking under a rotational shear load. This 'factory roof' morphology of the crack surface proved that the crack growth in a DSR bitumen sample is fundamentally controlled by the shear fatigue load rather than the 'edge instability'. The same morphology of bitumen cracking surfaces under a shear fatigue loading was reported in the previous studies (Hintz \& Bahia, 2013b; Shan, Tian, He, \& Ren, 2017). It is noted from Eq. (5) that the crack under a rotational shear load is initiated at the outer edge of the sample where the largest shear stress occurs. Thus the crack grows toward the centre of the sample once initiated.

Figure 4(b) shows how the crack length was determined from the bitumen cracking surface photos using an image analysis software Digimizer. The crack length can be determined 
following the below image-processing steps:

(1) The edge of the bitumen sample on photos was determined using the Circle to Center tool in Digimizer. Then the total area of the bitumen sample on photos can be measured in pixels and the corresponding radius ( $\left.r_{0 \mathrm{pi}}\right)$ of the sample was calculated using the total area.

(2) The intact area (uncracked portion) in the centre of the sample on photos was identified by defining a circumference as the circular boundary between the central uncracked area with a smooth surface and the ring cracked area with the rough surface. The area of this intact area is measured in pixels using the Circle to Center tool in Digimizer, which is then utilized to determine the effective radius ( $r \mathrm{Epi})$ of this intact area.

(3) The effective radius ( $\left.r_{\mathrm{Epi}}\right)$ measured in pixels was converted to the effective radius $\left(r_{\mathrm{E}}\right)$ in millimetres by Eq. (24). Note that the original radius $\left(r_{0}\right)$ for the laboratory tested sample equals $4 \mathrm{~mm}$.

$$
r_{E}=\frac{r_{E p i}}{r_{0 p i}} \cdot r_{0}
$$

(4) The crack length was defined as the difference between the original radius of the sample and the effective radius when the TS test completes. Thus, the crack length $(c)$ was obtained by

$$
c=r_{0}-r_{E}
$$

In the above image analysis procedure, the intact area and the effective radius of the sample were objectively measured by the Circle to Center tool in Digimizer software . The boundary between the central uncracked zone and the ring cracked zone was defined by users using a circle in software. It was found that difference of crack length determined by different researchers was negligible (less than 5\%), which indicates that the boundary definition is relatively objective and reliable. This is because that the boundary between the smooth and rough surfaces is very obvious in the images of cracking surfaces of bitumen sample, as shown in Figure 4.
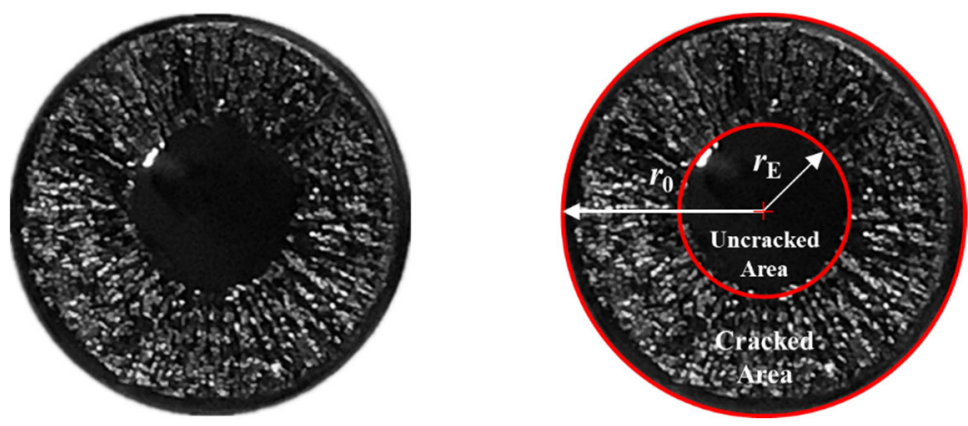
(a)

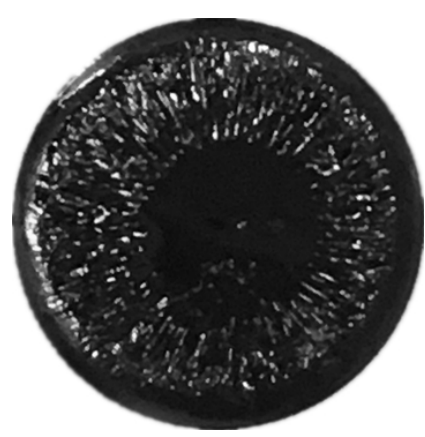

(c)

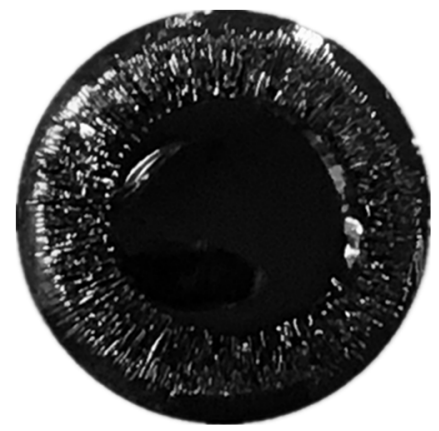

(d) (b)

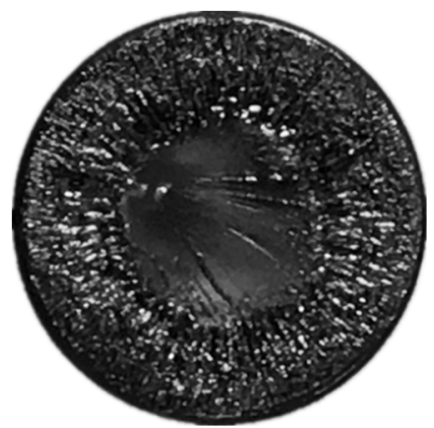

(e)

Figure 4. Images of cracking surfaces for bitumen sample after time sweep (TS) tests at $20{ }^{\circ} \mathrm{C}$ and 10 Hz. (a) Cracking morphology under 42000 load cycles at 5\% strain level for virgin unmodified bitumen 40/60 $\left(B_{v}\right)$. (b) Definition and measurement of the effective radius and crack length for $B_{v}$. (Crack length $c$ is determined by $c=r_{0}-r_{\mathrm{E}}$, where $r_{0}$ is the original radius and $r_{\mathrm{E}}$ is the effective radius of the uncracked area.) (c) Cracking morphology under 24000 load cycles at $\mathbf{7 \%}$ strain level for virgin polymer modified bitumen X-70 $\left(\mathrm{A}_{\mathrm{v}}\right)$. (d) Cracking morphology under 24000 load cycles at 5\% strain level for aged polymer modified bitumen X-70 $\left(\mathrm{A}_{\mathrm{a}}\right)$. (e) Cracking morphology under 24000 load cycles at 5\% strain level for aged unmodified bitumen 40/60 ( $\left.B_{a}\right)$.

\subsection{Comparison between calculated and measured crack length}

In order to validate the DSR-based crack growth (DSR-C) model, i.e., Eq. (23), the comparison between the calculated and measured results of the crack length was conducted at varying loading durations (where the test conditions, such as temperature, frequency and strain level were controlled unchanged) and at different test conditions (where the load cycle was selected as a constant), respectively.

The validation of the prediction model was firstly performed at varying loading durations in terms of load cycles. The TS tests were conducted at a constant strain (5\%) loading mode, $20{ }^{\circ} \mathrm{C}$ and $10 \mathrm{~Hz}$. Three duplicate samples need to be used to obtain the effective radiuses at three different number of load cycles. The TS test for the first sample was terminated at 7,200 cycles, the sample was pulled apart and the bitumen's cracking surface was imaged, and then the effective radius was measured following the Steps in Section 4.1 and the crack length was determined using Eq. (25). The other two duplicate samples were tested using the same procedure, but terminated at 24,000 and 42,000 load cycles, respectively, to obtain the crack surface images and determine the crack lengths. The shear moduli declining with the number of load cycles for the three samples of the two different bitumen materials (unaged X-70 and 
unaged 40/60) are presented in Figure 5 on which the crack surface images at the corresponding termination load cycles are also presented. It can be seen that the modulus curves of the three duplicate samples are overlapped each other in general, demonstrating the good repeatability of the fatigue damage tests. With the increase of load cycles, shear modulus declines rapidly at the first 200 load cycles and then starts a relatively slow decrease with the load cycle. The central intact area (defined by the red circles on the crack surface images) became smaller with the increase of load cycle, indicating a growth of crack within the bitumen samples in the TS tests.

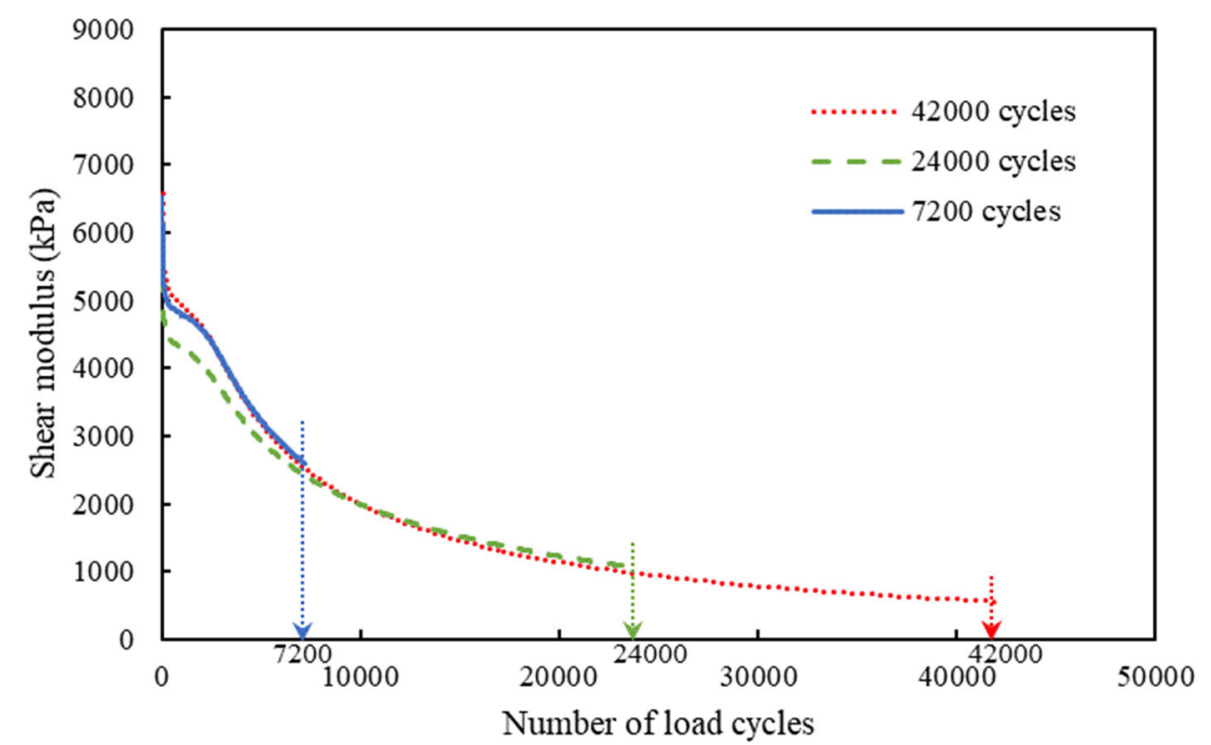

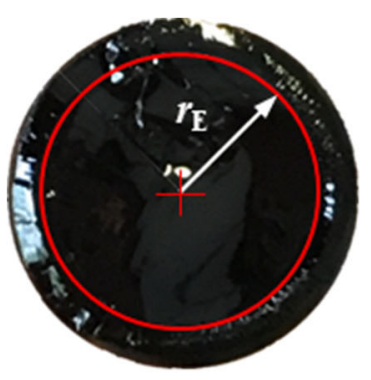

7,200 load cycles

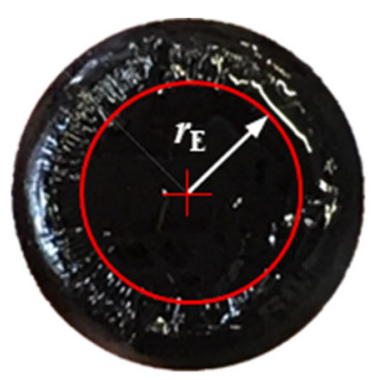

24,000 load cycles

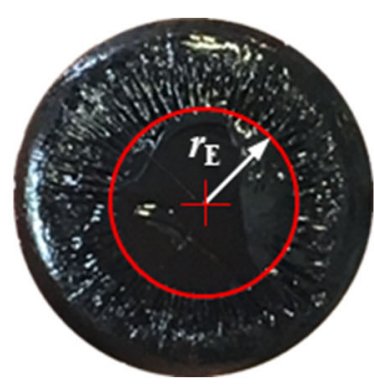

42,000 load cycles

(a) Polymer modified bitumen X-70 


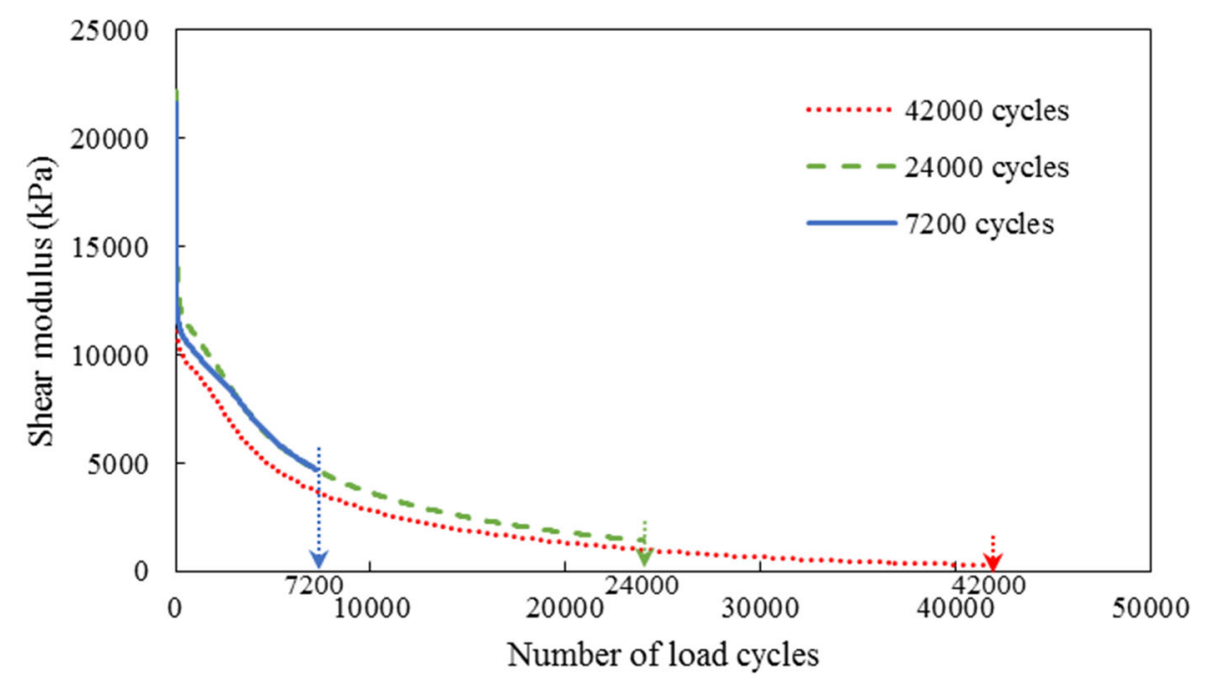

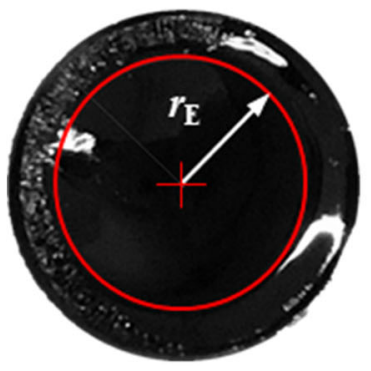

7,200 load cycles

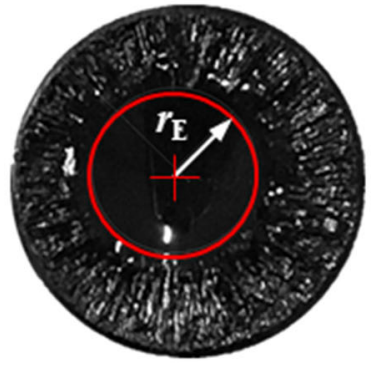

24,000 load cycles

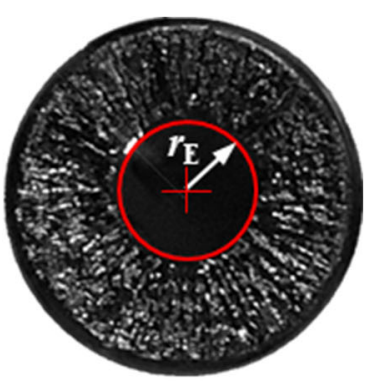

42,000 load cycles

(b) Virgin bitumen 40/60

Figure 5. Shear modulus vs. load cycles and cracking surface images for three duplicate samples terminated at different load cycles. (The time sweep fatigue tests were conducted at a controlled strain of $5 \%, 20{ }^{\circ} \mathrm{C}$ and $10 \mathrm{~Hz}$.)

The predicted effective radius and crack length were calculated by Eqs. (22) and (23), respectively, where the shear modulus $\left(\left|G^{*}\right|\right)$ and the phase angle $\left(\delta_{0}\right)$ of the bitumen at the undamaged condition were obtained from the linear amplitude sweep (LAS) test results and the shear modulus $\left(\left|G^{*}\right|\right)$ and the phase angle $\left(\delta_{\mathrm{N}}\right)$ of the bitumen at the damaged condition were obtained from the time sweep (TS) tests. The predicted results were compared with the experimental results measured from crack surface images in the TS tests. Table 2 shows the calculated and measured results for the effective radius and crack length under a controlled strain of $5 \%, 20{ }^{\circ} \mathrm{C}$ and $10 \mathrm{~Hz}$, based on the average result of two replicates in each condition. The crack length data were also plotted in Figure 6 to clearly compare the calculated and measured crack length, and the results of the two replicates at each load cycle were presented to show the consistency of the results. It was found that the predicted results using the Eq. (23) model were in a good agreement (the average difference is within $0.78 \%$ ) with the 
experimentally measured results for five of the six conditions, except for the unaged 40-60 bitumen at 7,200 load cycles. The calculated crack length of the unaged 40-60 bitumen at 7,200 load cycles was slightly greater $(0.176 \mathrm{~mm}$ or $13.69 \%)$ than the measured value. This is probably due to the fluctuation of the modulus at the crack initiation stage in the TS test that will be further studied and improved in the following work.

Table 2. Calculated vs. measured results for effective radius and crack length in time sweep tests at different load cycles for two bitumen materials (a controlled strain of $5 \%, 20{ }^{\circ} \mathrm{C}$ and $10 \mathrm{~Hz}$, averaged results of two replicates).

\begin{tabular}{|c|c|c|c|c|c|c|}
\hline \multirow{2}{*}{ Materials } & \multirow{2}{*}{\multicolumn{2}{|c|}{ Testing conditions }} & \multicolumn{2}{|c|}{ Effective radius (mm) } & \multicolumn{2}{|c|}{ Crack length (mm) } \\
\hline & & & Calculated & Measured & Calculated & Measured \\
\hline \multirow{4}{*}{$\begin{array}{c}\text { Unaged } \\
\mathrm{X}-70 \\
\text { bitumen }\end{array}$} & & 7200 cycles & 3.013 & 3.044 & 0.987 & 0.957 \\
\hline & $20^{\circ} \mathrm{C}$ & & & & & \\
\hline & $10 \mathrm{~Hz}$ & 24000 cycles & 2.435 & 2.433 & 1.565 & 1.567 \\
\hline & & 42000 cycles & 2.103 & 2.091 & 1.897 & 1.909 \\
\hline \multirow{4}{*}{$\begin{array}{c}\text { Unaged } \\
40-60 \\
\text { bitumen }\end{array}$} & & 7200 cycles & 2.534 & 2.710 & 1.466 & 1.290 \\
\hline & $20^{\circ} \mathrm{C}$ & & & & & \\
\hline & $10 \mathrm{~Hz}$ & 24000 cycles & 1.857 & 1.871 & 2.143 & 2.129 \\
\hline & & 42000 cycles & 1.403 & 1.403 & 2.597 & 2.597 \\
\hline
\end{tabular}

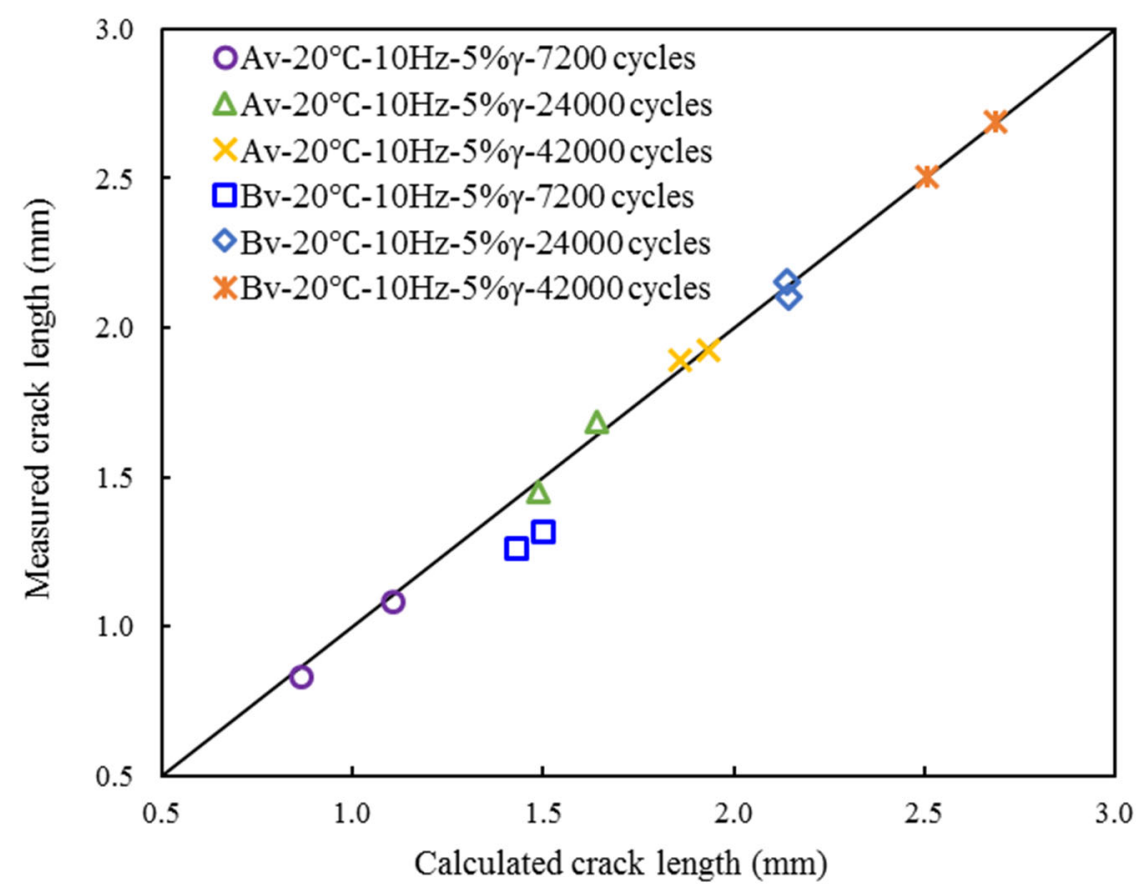

Figure 6. Comparison between calculated and measured crack length in time sweep tests at different 
load cycles for two bitumen materials. (Controlled strain of $5 \%, 20{ }^{\circ} \mathrm{C}$ and $10 \mathrm{~Hz}$, two replicates at each condition. Note: Av and Bv stand for two different bitumen materials, i.e., unaged X-70 bitumen and unaged $40 / 60$ bitumen.)

In addition to the number of load cycles, the DSR-based crack growth (DSR-C) model (Eq. 23) was further validated at different testing conditions including temperatures, frequencies and strain levels. Two bitumen materials at unaged and aged conditions were used in the time sweep tests which were all terminated at the same load cycle of 24,000. Table 3 compares the calculated and measured values for effective radius and crack length. Figure 7 shows the comparison between the calculated and measured crack length for the two replicates at each condition. It can be seen that the predicted results agreed well with the experimental measurements with the average difference within $0.68 \%$. This good agreement at different conditions indicates that the developed mechanics-based DSR-C model is capable of accurately predicting the crack length in bitumen under different testing conditions and can be used for quantifying the bitumen's fatigue cracking performance.

Table 3. Calculated vs. measured results for effective radius and crack length in time sweep tests at different conditions (all terminated at 24,000 load cycles and averaged results of two replicates).

\begin{tabular}{ccccc}
\hline \multirow{2}{*}{ Testing conditions } & \multicolumn{2}{c}{ Effective radius (mm) } & \multicolumn{2}{c}{ Crack length (mm) } \\
Calculated & Measured & Calculated & Measured \\
\hline $\mathrm{A}_{\mathrm{v}}-20^{\circ} \mathrm{C}-10 \mathrm{~Hz}-5 \% \gamma-24000$ cycles & 2.435 & 2.433 & 1.565 & 1.567 \\
$\mathrm{~A}_{\mathrm{v}}-15^{\circ} \mathrm{C}-10 \mathrm{~Hz}-5 \% \gamma-24000$ cycles & 2.300 & 2.318 & 1.700 & 1.682 \\
$\mathrm{~A}_{\mathrm{v}}-20^{\circ} \mathrm{C}-20 \mathrm{~Hz}-5 \% \gamma-24000$ cycles & 2.356 & 2.322 & 1.644 & 1.678 \\
$\mathrm{~A}_{\mathrm{v}}-20^{\circ} \mathrm{C}-10 \mathrm{~Hz}-7 \% \gamma-24000$ cycles & 1.872 & 1.860 & 2.128 & 2.140 \\
$\mathrm{~B}_{\mathrm{v}}-20^{\circ} \mathrm{C}-10 \mathrm{~Hz}-5 \% \gamma-24000$ cycles & 1.857 & 1.871 & 2.143 & 2.129 \\
$\mathrm{~A}_{\mathrm{a}}-20^{\circ} \mathrm{C}-10 \mathrm{~Hz}-5 \% \gamma-24000$ cycles & 2.285 & 2.286 & 1.715 & 1.714 \\
$\mathrm{~B}_{\mathrm{a}}-20^{\circ} \mathrm{C}-10 \mathrm{~Hz}-5 \% \gamma-24000$ cycles & 1.828 & 1.823 & 2.172 & 2.177 \\
\hline
\end{tabular}

Note: $\mathrm{Av}, \mathrm{Bv}, \mathrm{Aa}$ and $\mathrm{Ba}$ stand for the unaged X-70 bitumen, the unaged 40/60 bitumen, the aged X70 bitumen and the aged 40/60 bitumen, respectively.

Table 3 and Figure 7 also show that the crack length is greater by $9.32 \%, 7.34 \%, 7.04 \%$ or $36.53 \%$ when the bitumen became aged, the temperature went lower, the loading frequency increased or the strain levels increased. This means the bitumen is subjected to a more severe fatigue damage when the loading level is increased or the material itself becomes relatively stiffer such as undergoing an oxidative ageing, a low temperature, or a high frequency. These observations are consistent with the common understanding and the existing studies of the fatigue behaviour of a bitumen material (Shan, Tian, He, \& Ren, 2017; Miró, Martínez, 
Moreno-Navarro, \& Rubio-Gámez, 2015). It is also noted from Figures 6 and 7 that the results at each testing condition have a good consistency between the two replicates, which indicate that the variation is minor for the fatigue damage tests done in this study.

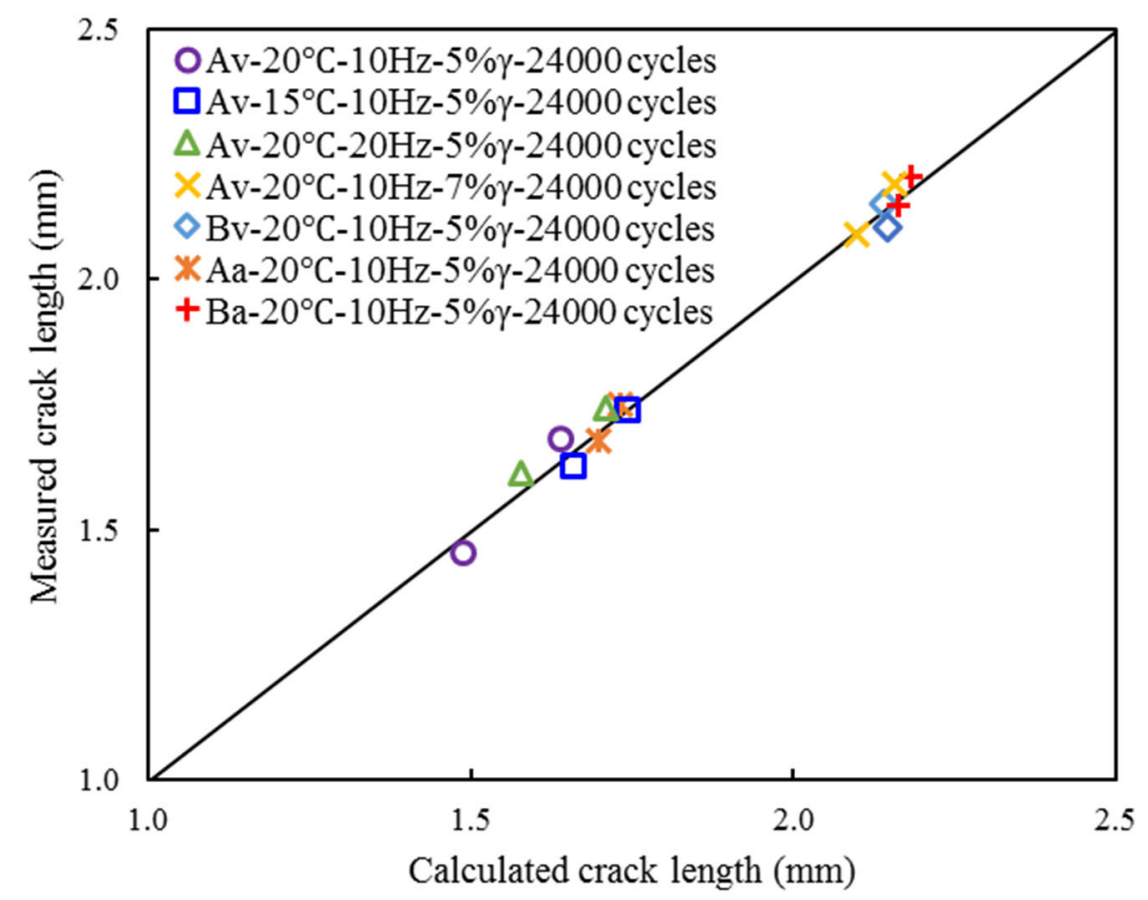

Figure 7. Comparison between calculated and measured crack length in time sweep tests at different conditions. (All terminated at 24,000 load cycles; two replicates at each condition. Note: Av, Bv, Aa and Ba stand for unaged X-70 bitumen, unaged 40/60 bitumen, aged X-70 bitumen and aged 40/60 bitumen, respectively.)

\subsection{Crack growth in bitumen}

In order to understand the fatigue damage mechanism, the crack growth in the bitumen sample during the shear fatigue process was further analysed using the developed DSR-C model (Eq. 23) and the crack surface images. Figure 8 shows the crack growth curves of the unaged X-70 bitumen and the unaged 40/60 bitumen under a shear fatigue loading. It can be seen that the crack has a quite stable growth as the number of load cycle increases in the tests.

The crack growth process shown in Figure 8 can be divided into three stages: the initial transition period (Stage I), the steady growth period (Stage II), and the rapid growth period (Stage III). The crack at each stage presents significantly different growth characteristics. In the transition Stage I (approximately within the first 200 cycles), the crack length increases and shows a certain fluctuation with the number of load cycle. This is due to the unstable flow at the edge of the bitumen sample that is subjected to the largest shear stress in the crack initiation 
period according to the liner stress distribution shown in Eq. (5). In the steady growth Stage II (approximately from 200 to 2,000 cycles), the crack length increases slowly but at a constant rate in the semi-logarithmic coordinate, which indicates the bitumen start to consistently resist the crack growth due to the material viscoelastic and cohesive property. As the crack grows toward the centre of the sample, the crack length reaches a critical point at a separating load cycle $\left(N_{f}\right)$, after which the rapid growth Stage III starts where the crack length increases rapidly until the sample is completely damaged or the loading is removed. The separating load cycle $\left(N_{f}\right)$ can be regarded as the fatigue life of the bitumen. By linking Figure 8 with Figure 5 using the crack growth model in Eq. (23), it can be concluded that the degradation in material properties (the decrease of shear modulus and the increase of phase angle) of the bitumen under the shear fatigue loading results from the crack growth that initiates from the outer edge toward the centre of the sample in the DSR test.

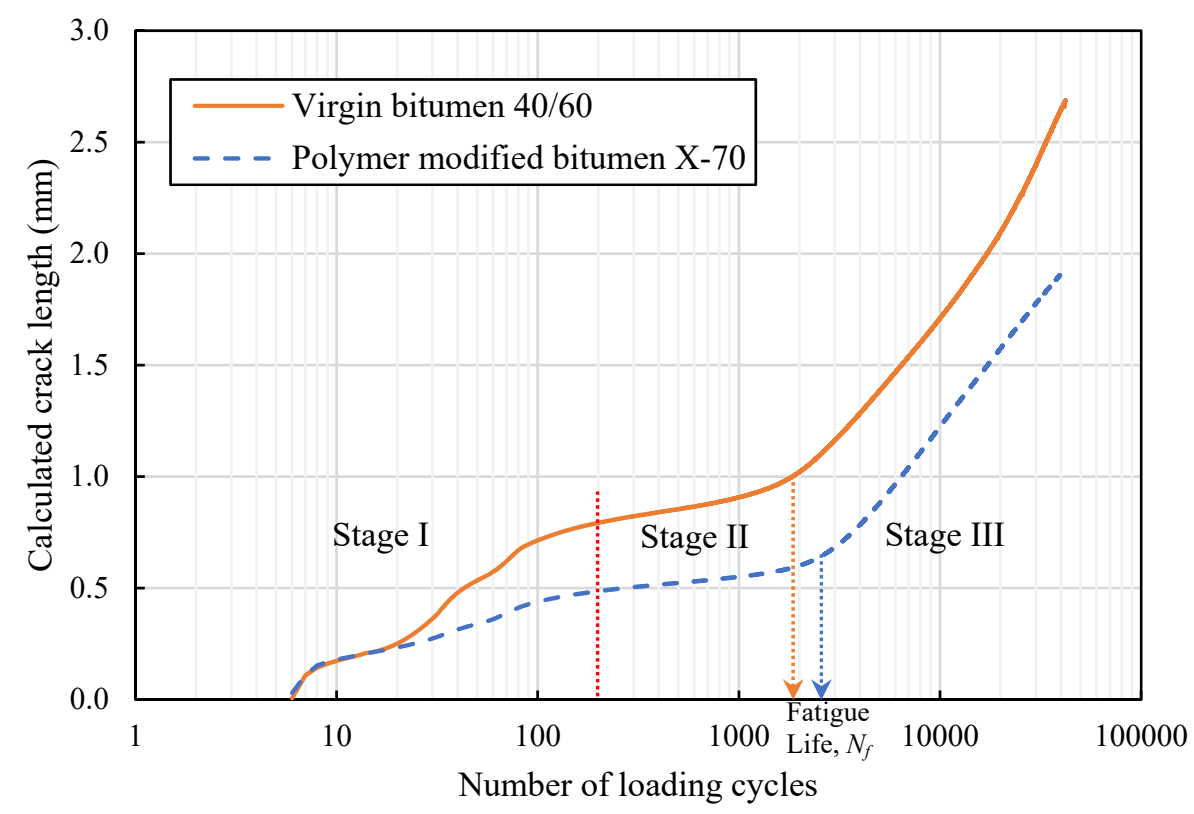

Figure 8. Crack length in bitumen vs. number of load cycle under a rotational shear fatigue load. (The crack length is determined by the crack growth model in Eq. (23) with model parameters determined by the time sweep (TS) tests at a constant strain of $5 \%, 20^{\circ} \mathrm{C}$ and $10 \mathrm{~Hz}$.)

It is also clear from Figure 8 that the unaged X-70 bitumen and the unaged 40/60 bitumen showed different fatigue life (i.e., $N_{f}$ ) when subjected to the same loading conditions. Bitumen $\mathrm{X}-70$ which is softer with a lower modulus (see modulus values in Figure 5) has less crack length and longer fatigue life compared to the Bitumen 40/60 which is relatively stiffer with a greater modulus. Thus, there is a great potential to use the DSR-based crack growth (DSR-C) model (Eq. 23) to characterise fatigue resistance of the different bitumen materials. The DSR- 
$\mathrm{C}$ model in future study will be used to develop a direct index based on modulus and phase angle at both undamaged and damaged conditions to evaluate bitumen's fatigue performance and the validations of the model in more different types of bitumen materials.

\section{Conclusions}

A dynamic shear rheometer (DSR) based crack growth (DSR-C) model was developed for the prediction of the crack growth in the viscoelastic bitumen specimens subjected a rotational shear fatigue load. Equilibrium principle of damage mechanics based on dissipated strain energy (DSE) were used to construct the DSR-C model to obtain the crack length. The following conclusions were drawn from the research.

(1) The DSR-based crack growth (DSR-C) model based on damage mechanics is capable of accurately predicting the crack length in bitumen under a rotational shear fatigue load at different testing conditions and for different bitumen materials.

(2) The developed DSR-C model can be applied to investigate the effects of the loading (strain) level, aging, temperature and loading frequency on the fatigue performance of bitumen. Bitumen will be subjected to a more severe fatigue damage with the increasing crack length by $9.32 \%, 7.34 \%, 7.04 \%$ or $36.53 \%$ when the bitumen became aged, the temperature went lower, the loading frequency increased or the strain levels increased .

(3) The three-stage crack growth analysis based on the DSR-C model is able to effectively quantify the fatigue cracking performance of different bitumens.

(4) The degradation in material properties of bitumen under a shear fatigue load results from the crack growth that initiates from the outer edge of the sample toward the centre of the sample in the DSR test.

The on-going research include the practical application of the developed DSR-C model to quantify and differentiate the fatigue performances of various bituminous binders. The crack length predicted by the DSR-C model will serve as a direct evaluation parameter of the bitumen's resistance to the fatigue cracking. Future study will be continued using the crack length predicted by the DSR-C model to characterise and model the crack evolution in bitumen, which can be applied to predict the cracking rate in bitumen.

\section{Acknowledgement}

The authors would like to gratefully acknowledge the National Asphalt Research Consortium (NARC) for their financial support to this study. 


\section{References}

AASHTO. (2012). Standard method of test for determining the rheological properties of asphalt binder using a dynamic shear rheometer (DSR). T 315, Washington, DC.

Aboutorabi, H., Ebbot, T., \& Gent, A.N. (1998). Crack growth in twisted rubber disks. Part I: Fracture energy calculations. Rubber Chemistry and Technology, 71(1), 76-83.

Anderson, D. A., Hir, Y., Marasteanu, M., Planche, J. P., Martin, D., \& Gauthier, G. (2001). Evaluation of fatigue criteria for asphalt binders. Transportation Research Record: Journal of the Transportation Research Board, 1766, 48-56.

Anderson, D. A., \& Kennedy, T. (1993). Development of SHRP binder specification. Journal of the Association of Asphalt Paving Technologists, 62, 481-507.

Bahia, H. U., Zeng, D. I., Khatri, H., Zhai, M. A., \& Anderson, R. M. (2001). Characterization of Modified Asphalt Binders in Superpave Mix Design (NCHRP Report 459). Washington, DC: National Cooperative Highway Research Program.

Bahia, H. U., Zhai, H., Zeng, M., Hu, Y., \& Turner, P. (2001). Development of binder specification parameters based on characterization of damage behavior. Journal of the Association of Asphalt Paving Technologists, 70, 442-470.

Bonnetti, K.S., Nam, K., \& Bahia, H.U. (2002). Measuring and defining fatigue behavior of asphalt binders. Transportation Research Record: Journal of the Transportation Research Board, 1810, 33-43.

Gao, Y., Dong, M., Li, L., Wang, L., \& Sun Z. (2015). Interface effects on the creep characteristics of asphalt concrete. Construction and Building Materials, 96, 591-598.

Gao, Y., Zhang, Y., Yang, Y., Zhang, J., \& Gu, F. (2019). Molecular dynamics investigation of interfacial adhesion between oxidised bitumen and mineral surfaces. Applied Surface Science, 479, 449-462.

Ghuzlan, K., \& Carpenter, S. (2000). Energy-derived, damage-based failure criterion for fatigue testing. Transportation Research Record: Journal of the Transportation Research Board, 1723, 141-149.

Hintz, C., \& Bahia, H. (2013a). Simplification of linear amplitude sweep test and specification parameter. Transportation Research Record: Journal of the Transportation Research Board, 2370, 10-16.

Hintz, C., \& Bahia, H. (2013b). Understanding mechanisms leading to asphalt binder fatigue in the dynamic shear rheometer. Road Materials and Pavement Design, 14, 231-251.

Hintz, C., Velasquez, R., Johnson, C., \& Bahia, H. (2011). Modification and validation of linear amplitude sweep test for binder fatigue specification. Transportation Research Record: Journal of the Transportation Research 
Board, 2207, 99-106.

Hintz, C., Velasquez, R., Bahia, H. B., \& Stimilli, A. (2011). Normal stresses in dynamic shear rheometer testing for binder damage. University of Wisconsin - Madison Modified Asphalt Research Center (MARC) white paper.

Keentok, M., \& Xue, S. (1999). Edge fracture in cone-plate and parallel plate flows. Rheologica Acta, 38(4), 321348.

Lytton, R.L., Zhang, Y., Gu, F., \& Luo X. (2018) Characteristics of damaged asphalt mixtures in tension and compression. International Journal of Pavement Engineering, 19 (3) 292-306.

Martono, W., Bahia, H.U., \& Angelo, J.D. (2007). Effect of testing geometry on measuring fatigue of asphalt. ASCE Journal of Materials in Civil Engineering, 19, 746-752.

Miró, R., Martínez, A.H., Moreno-Navarro, F., \& Rubio-Gámez, M. (2015). Effect of ageing and temperature on the fatigue behaviour of bitumens. Materials \& Design, 86, 129-137.

Planche, J. P., Anderson, D. A., Gauthier, G., Hir, Y. M. L., \& Martin, D. (2004). Evaluation of fatigue properties of bituminous binders. Materials and Structures, 37, 356-359.

Safaei, F., \& Castorena, C. (2016). Temperature effects of linear amplitude sweep testing and analysis. Transportation Research Record: Journal of the Transportation Research Board, 2574, 92-100.

Safaei, F., \& Castorena, C. (2017). Material nonlinearity in asphalt binder fatigue testing and analysis. Materials \& Design, 133, 376-389.

Safaei, F., Castorena, C., \& Kim, Y. R. (2016). Linking asphalt binder fatigue to asphalt mixture fatigue performance using viscoelastic continuum damage modeling. Mechanics of Time-Dependent Materials, 20, 299-323.

Shan, L., Tian, S., He, H., \& Ren, N. (2017). Internal crack growth of asphalt binders during shear fatigue process. Fuel, 189, 293-300.

Shen, S., Airey, G. D., Carpenter, S. H., \& Huang, H. (2006). A dissipated energy approach to fatigue evaluation. Road Materials and Pavement Design, 7 (1), 47-69.

Shen, S., \& Carpenter, S. (2005). Application of the dissipated energy concept in fatigue endurance limit testing. Transportation Research Record: Journal of the Transportation Research Board, 1929, 165-173.

Shen, S., Chiu, H.M., \& Huang, H. (2010). Characterization of fatigue and healing in asphalt binders. $A S C E$ Journal of Materials in Civil Engineering, 22(9), 846-852.

Tsai, B.W., \& Monismith, C. (2005). Influence of asphalt binder properties on the fatigue performance of asphalt 
concrete pavements. Journal of the Association of Asphalt Paving Technologists, 74, 733-790.

Tschegg, E., Ritchie, R., \& McClintock, F. (1983). On the influence of rubbing fracture surface on fatigue crack propagation in mode III. International Journal of Fatigue, 5(1), 29-35.

Wang, C., Castorena, C., Zhang J., \& Kim, Y. R. (2015). Unified failure criterion for asphalt binder under cyclic fatigue loading. Road Materials and Pavement Design, 16:sup2, 125-148, DOI: 10.1080/14680629.2015.1077010.

Wang, C., Zhang, H., Castorena, C., Zhang, J., \& Kim, Y. R. (2016). Identifying fatigue failure in asphalt binder time sweep tests. Construction and Building Materials, 121, 535-546.

Zhang, Y., Gu, F., Birgisson, B., \& Lytton, R.L. (2018) Modelling cracking damage of asphalt mixtures under compressive monotonic and repeated loads using pseudo J-integral Paris' law. Road Materials and Pavement Design, 19 (3) 525-535.

Zhang, Y., Luo, X., Luo, R., \& Lytton, R.L. (2014) Crack initiation in asphalt mixtures under external compressive loads. Construction and Building Materials, 72 94-103.

Zhou, F., Mogawer, W., Li, H., Andriescu, A., \& Copeland, A. (2013). Evaluation of fatigue tests for characterizing asphalt binders. ASCE Journal of Materials in Civil Engineering, 25, 610-617. 